Communications in Physics, Vol. 23, No. 2 (2013), pp. 179-184

\title{
THE THIN FILM PVA - BROMOCRESOL GREEN DOSIMETER
}

\author{
NGUYEN VAN DUNG \\ Hanoi University of Minning and Geology \\ Dong Ngac, Tu Liem, Hanoi \\ Received 16 May 2013; revised manuscript received 21 June 2013 \\ Accepted for publication 27 June 2013
}

\begin{abstract}
The thin film PVA (polyvinyl alcohol) - bromocresol green $(\sim 15 \mu \mathrm{m})$ dosimeter was made for the applications in radiation technology. It's parameters before and after gamma irradiation have been studied using optical spectrometer UV-VIS JASCO-V-350 and film densitometer $X$-Rite Model 301. The results show that the specific wavelength of thin film is $\sim 625 n m$ and the sensitivity of thin film dosimeter is $\sim 0.013 \times 10^{-3} G^{-1}$ in the dose range from 1 kGy to $140 \mathrm{kGy}$. The dose response function of dosimeter was clearly described by the theory of energy transfer model.
\end{abstract}

\section{INTRODUCTION}

Polyvinyl alcohol is excellent matrix for radiochromic centres and widely used for high dose dosimetry purpose [1-3].

An important feature of a dosimeter is its dose-response, which is often expressed as a set of exposure calibration factor at different absorbed doses. A desirable characteristic of dosimeter must be the minimal variation in sensitivity over a wide range of doses.

The clear PVA films were studied for high dose dosimetry in [4]. The dyed PVA films with multi-wavelengths in absorbance spectrum were also studied $[5,7]$.

In present work the dose-response of PVA film dyed by bromocresol green is introduced. The sensitivity of the film is determined in a wide range of doses.

\section{DOSE-RESPONSE OF THE FILMS}

According the energy transfer model, an interested dosimeter is considered as a collective acting aggregate of numerous identical radiation sensitive elements. These sensitive elements are uniformly distributed in the dosimeter [6].

The gamma irradiation leads to the formation of activated elements from the sensitive ones. The correlation between number of activated elements $\mathrm{n}(\mathrm{D})$ at absorbed dose $\mathrm{D}$, dose rate $\mathrm{D}^{\prime}$ and the number of the radiation sensitive elements $\mathrm{C}$ can be written as follows:

$$
n(D)=n_{s}\left[1-\exp \left(-k_{0} \frac{D}{D^{\prime}}\right)\right]+n_{0} \exp \left(-k_{0} \frac{D}{D^{\prime}}\right)
$$

and

$$
n_{s}=\frac{p C}{p-q},
$$


where $\mathrm{k}_{0}$ is the probability that one sensitive element will be activated and detectable per unit of time in irradiation process; $\mathrm{n}_{s}$ and $n_{0}$ are the numbers of activated elements at $D=\infty$ and $D=0$, respectively; $p$ and $q$ is probability that one sensitive element will be activated and reactivated per unit of time, respectively and

$$
k_{0}=p-q .
$$

The formula (1) is the dose - response of the film dosimeter in the electron equilibrium during irradiation. Note that the activated elements $n(D)$ is proportional to the film absorbance and optical density, that Eqs. 1-3 are also applied for these mentioned parameters.

The dose-response of the films can be also described by the theory of track structure:

$$
n(D)=c\left(1-\exp \left(-\frac{D}{D_{37}}\right)\right)
$$

where $D_{37}$ is the dose at which dose - response get 63 percent of saturation level. It is show that

$$
D_{37}=\frac{D^{\prime}}{k_{0}}
$$

\section{EXPERIMENTAL}

Polyvinyl alcohol (- $\left.\mathrm{CH}_{2} \mathrm{CHOH}-\right)_{1500}$ was dissolved in ionized water. The mixture was added by $0.005 \mathrm{~g}$ bromocresol green $\mathrm{C}_{21} \mathrm{H}_{13} \mathrm{Br}_{4} \mathrm{O}_{5} \mathrm{~S}$, heated and stirred at $80^{\circ} \mathrm{C}$ for 30 min to make a homogeneous solution containing 1.5 percent PVA by weight. The resulting mixture was poured on a flat glass plate to form $15-20 \mu \mathrm{m}$ thick film by naturally drying at the room temperature.

The films of 3 pieces with the size of $40 \times 10 \mathrm{~mm}$ are prepared and put in polyethylene pouches for use.

The pouches of dyed PVA films were irradiated under gamma rays of ${ }^{60} \mathrm{Co}$ source of the Irradiation Centre in Cau Dien district. Irradiation was carried out at doses from $1 \mathrm{kGy}$ to $140 \mathrm{kGy}$ with dose rate of $0.9 \mathrm{kGyh}^{1}$. The electron equilibrium was achieved by using PMMA sandwiched slabs.

The absorbances $\mathrm{A}_{0}$ and $\mathrm{A}_{c}$ of the films before and after irradiation respectively were measured by spectrophotometer UV-VIS JASCO-V-350 (JASCO, Japan) with wavelength accuracy $\pm 0.2 \mathrm{~nm}$. The film densities were measured by the densitometer X-Rite Model 301.

A ratio of specific absorbances $A_{R}$ is used for correction of film thickness variation

$$
A_{R}=\frac{\frac{A}{t}}{\frac{A_{0}}{t}}=\frac{A}{A_{0}},
$$

where $t$ is thickness of the film.

The sensitivity of the film is defined as follows:

$$
k=\frac{k_{0}}{D^{\prime}} .
$$




\section{RESULTS AND DISCUSSION}

\section{Study on fading effect (reducing effects of optical density against time)}

To investigate the stability of the dose-response after the end of irradiation, the PVA bromocresol green films are preserved at the environmental temperature and humidity. Then the optical density of each sample was measured against time to evaluate degradation of the dose-response. This examination takes place within 30 days.

The test results decline optical density of a PVA-bromocresol green film in $80 \mathrm{kGy}$ dose given in Fig. 1

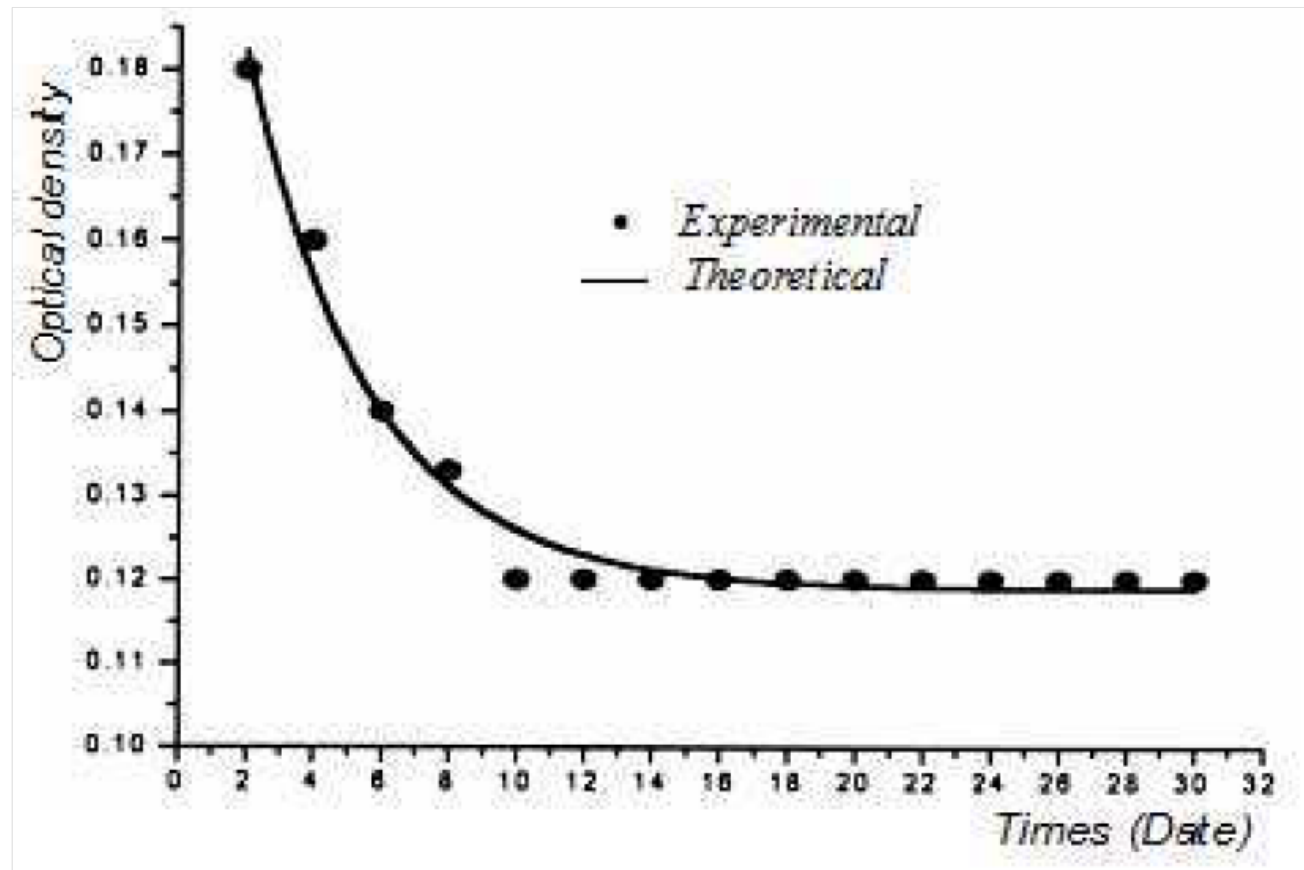

Fig. 1. Degradation of optical density for a PVA -bromocresol green film irradiated at $80 \mathrm{kGy}$ dose.

The graph shows that the optical density decreases during the first 10 days and then it is relatively stable. The degradation curve was exactly described by the typical function of the energy transfer model, so dosimeters can use any period after irradiation $[6]$.

\section{Absorption spectra and doses response of PVA film bromocresol green}

The specific absorption spectra of the PVA film dyed by bromocresol green before and after irradiation at $D=40 \mathrm{kGy}$ are introduced in Fig. 2 and Fig. 3.

Generally, the values of the specific absorbance peaks at $625 \mathrm{~nm}$ are strongly decreased against doses (Figures 4-5). 


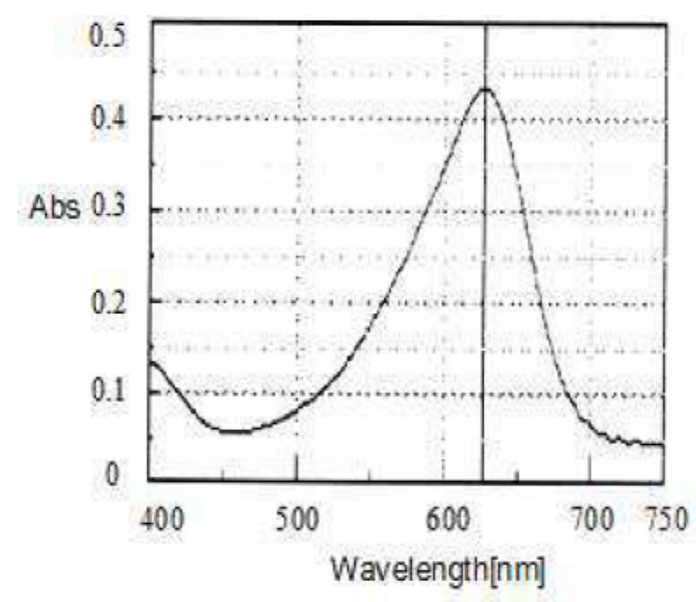

Fig. 2. The absorption spectrum of PVA bromocresol green film before irradiation

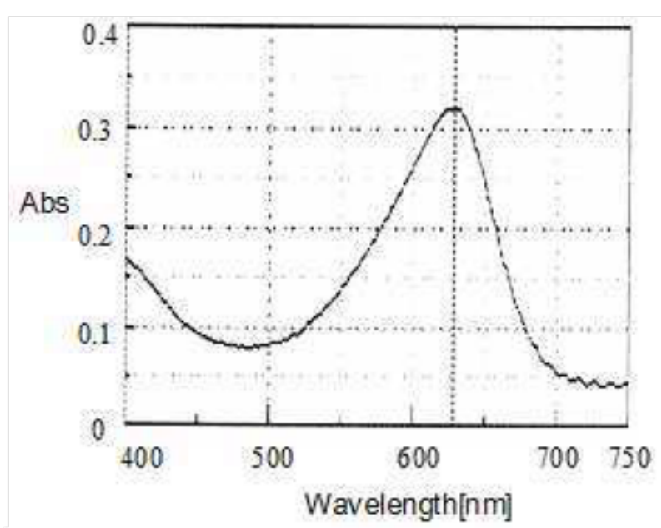

Fig. 4. The absorption spectrum of PVA bromocresol green film at $D=100 \mathrm{kGy}$

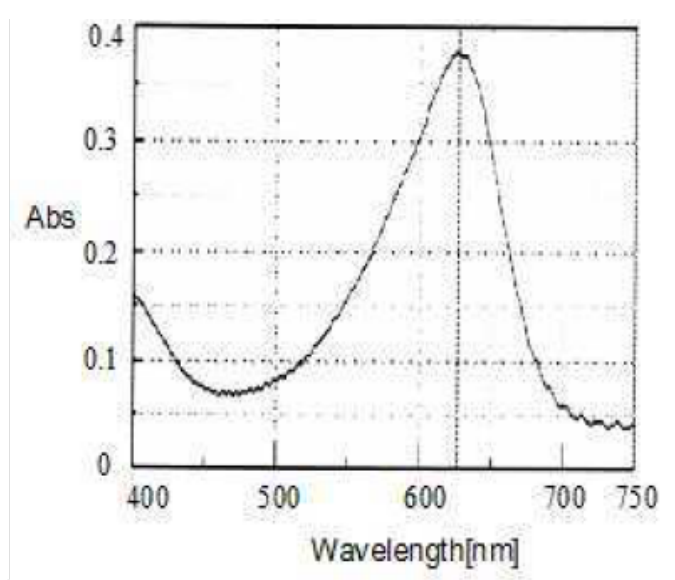

Fig. 3. The absorption spectrum of PVA bromocresol green under ${ }^{60} \mathrm{Co}$ gamma rays irradiation at $D=40 \mathrm{kGy}$

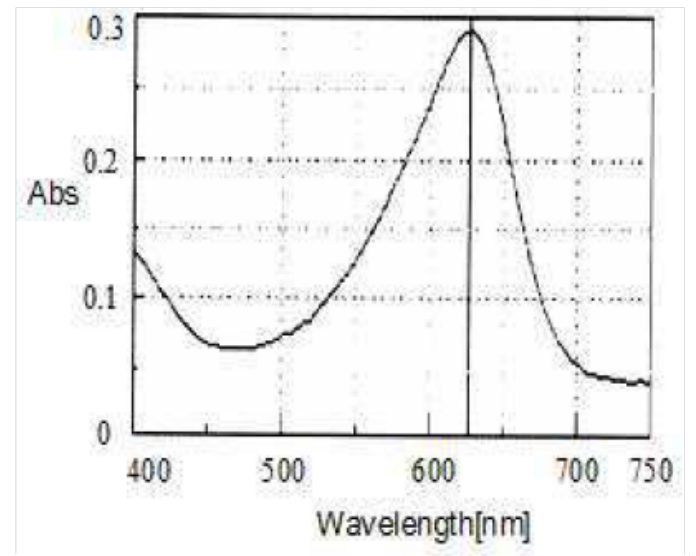

Fig. 5. The absorption spectrum of PVA bromocresol green film at $D=140 \mathrm{kGy}$

The above figure show the absorption spectra near the specific peak of PVA- bromocresol green films before and after irradiation, i.e. from $0 \mathrm{kGy}$ to $140 \mathrm{kGy}$. The corresponding specific absorbance values are changed from 0.425 to 0.295 . The experimental optical densities before $(\mathrm{OD})_{0}$ and after irradiation $(\mathrm{OD})_{c}$, as when as a ratio $(\mathrm{OD})_{R}=(\mathrm{OD})_{c} /(\mathrm{OD})_{0}$ of the PVA-bromocresol green films are introduced in Table 1.

The fitting of the value OD from Table 1 to Formula (1) provides the dose-response of PVA-bromocresol green films with following coefficients:

$n_{s}=0.489 \pm 0.020, n_{0}=1.142 \pm 0.008, k=0.014 \pm 0.001, R^{2}=0.987$.

The correlation coefficient $R^{2} \approx 1$ shows a good agreement between the experimental data and theoretical description. 
Table 1. The optical density after irradiation $(\mathrm{OD})_{c}$, before irradiation $(\mathrm{OD})_{0}$ and ratio $(\mathrm{OD})_{R}=(\mathrm{OD})_{c} /(\mathrm{OD})_{0}$

\begin{tabular}{|l|l|l|l|}
\hline \multirow{2}{*}{ Dose $(\mathrm{kGy})$} & \multicolumn{2}{|c|}{ Optical density $(\mathrm{OD})$} & \multirow{2}{*}{$\begin{array}{l}\text { Optical density } \\
\text { ratio (OD) }\end{array}$} \\
\cline { 2 - 3 } & $(\mathrm{OD})_{0}$ & $(\mathrm{OC})_{c}$ & \\
\hline 1 & 0.167 & 0.190 & 1.138 \\
\hline 10 & 0.180 & 0.193 & 1.072 \\
\hline 20 & 0.160 & 0.157 & 0.981 \\
\hline 30 & 0.173 & 0.163 & 0.942 \\
\hline 40 & 0.170 & 0.147 & 0.865 \\
\hline 50 & 0.160 & 0.130 & 0.813 \\
\hline 60 & 0.203 & 0.160 & 0.788 \\
\hline 70 & 0.200 & 0.150 & 0.750 \\
\hline 80 & 0.220 & 0.160 & 0.727 \\
\hline 90 & 0.200 & 0.140 & 0.700 \\
\hline 100 & 0.170 & 0.110 & 0.647 \\
\hline 110 & 0.173 & 0.110 & 0.636 \\
\hline 120 & 0.160 & 0.100 & 0.625 \\
\hline 130 & 0.140 & 0.086 & 0.614 \\
\hline 140 & 0.143 & 0.083 & 0.580 \\
\hline & & & \\
\hline
\end{tabular}

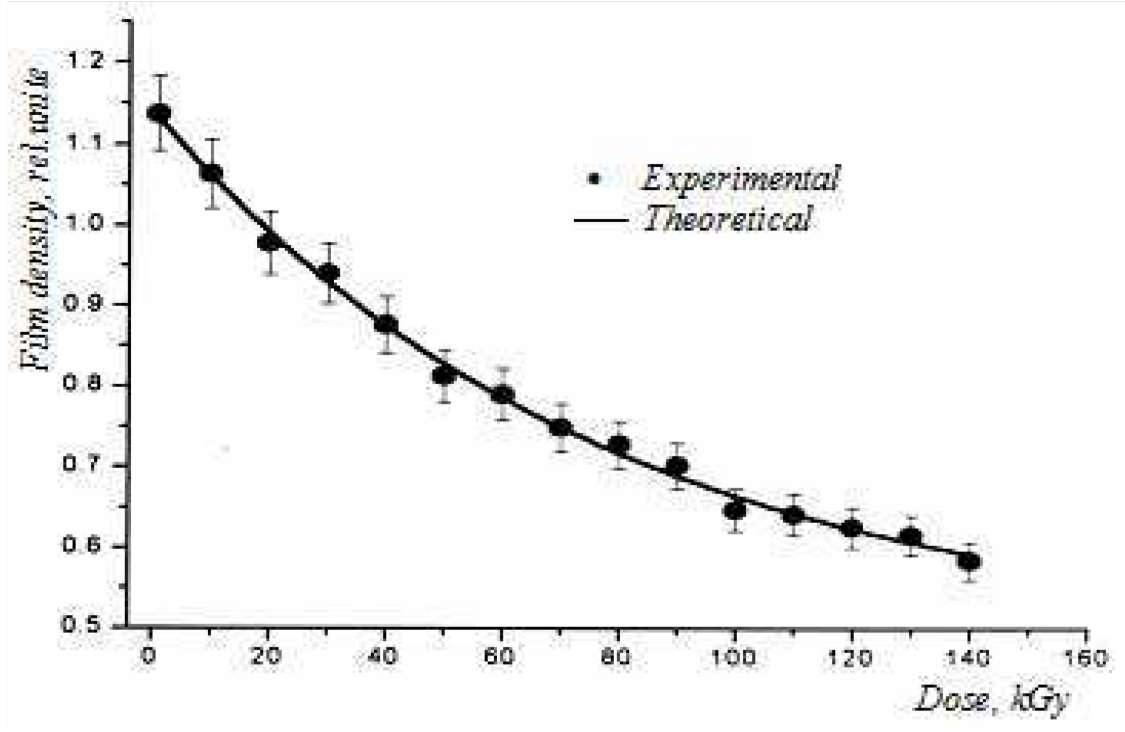

Fig. 6. The dose-response of the PVA- bromocresol green film.

\section{CONCLUSION}

The PVA- bromocresol green films with defined dose- response can be used as highdose dosimeter and monitor. It's dose-response under gamma irradiation described by the energy transfer model with the sensitivity $k=0.014 \pm 0.001 \mathrm{kGy}^{-1}$. 


\section{REFERENCES}

[1] Lavrentovich. Y. I, Levon A. I, Mel'nikova G. N. and Kabakchi A. M. Soviet Atomic Energy 19, (1965) 1189.

[2] Hubner K. and Prokert K. Isotopenpraxis 2(1971) 43.

[3] Chung W.H and Miller A. Nuclear Technology 106(1994) 5.

[4] Tran Dai Nghiep, Kojima T., Nguyen Trieu Tu and Tran Vien Ha, Comm. Phys. 7 (1) (1997) 14.

[5] Tran Dai Nghiep. Comm. Phys. 8(4) (1998) 237.

[6] Tran Dai Nghiep and T. Kojima, Comm. Phys. 6 (2) (1996) 5.

[7] N. T. Tu, N. V. Dung and T. D. Nghiep, Int. J. Low Radiation, 6(3) (2009) 177-184. 